Self-consistent application of ion cyclotron wall conditioning for co-deposited layer removal and recovery of tokamak operation on TEXTOR

This content has been downloaded from IOPscience. Please scroll down to see the full text. 2013 Nucl. Fusion 53123001

(http://iopscience.iop.org/0029-5515/53/12/123001)

View the table of contents for this issue, or go to the journal homepage for more

Download details:

IP Address: 193.190.205.100

This content was downloaded on 30/01/2014 at 13:59

Please note that terms and conditions apply. 


\title{
Self-consistent application of ion cyclotron wall conditioning for co-deposited layer removal and recovery of tokamak operation on TEXTOR
}

\author{
T. Wauters ${ }^{1}$, S. Möller ${ }^{2}$, A. Kreter ${ }^{2}$, M. Rubel ${ }^{3}$, A.G. Carrasco ${ }^{3}$, \\ K. Crombé ${ }^{1}$, D. Douai ${ }^{4}$, M. Freisinger ${ }^{2}$, D. Ivanova ${ }^{3}$, D. Kogut ${ }^{4}$, \\ R. Koslowski ${ }^{2}$, A. Lyssoivan ${ }^{1}$, D. Nicolai ${ }^{2}$, P. Petersson ${ }^{3}$, \\ V. Philipps ${ }^{2}$, M. Rack ${ }^{2}$, H. Reimer ${ }^{2}$, G. Sergienko ${ }^{2}$ and M. Vervier ${ }^{1}$ \\ ${ }^{1}$ LPP-ERM/KMS, Association Euratom-Belgian State, 1000 Brussels, Belgium \\ ${ }^{2}$ IEF-Plasmaphysik FZ Jülich, Euratom Association, 52425 Jülich, Germany \\ ${ }^{3}$ Alfvén Laboratory, Royal Institute of Technology, Association EURATOM-VR, \\ Stockholm, Sweden \\ ${ }^{4}$ CEA, IRFM, Association Euratom-CEA, 13108 St Paul lez Durance, France \\ E-mail: t.wauters@fz-juelich.de
}

Received 7 April 2013, accepted for publication 7 October 2013

Published 4 November 2013

Online at stacks.iop.org/NF/53/123001

\begin{abstract}
This paper presents a demonstration experiment of ion cyclotron wall conditioning (ICWC) on TEXTOR covering all ITER wall conditioning aims and discusses the implications for ITER. $\mathrm{O}_{2} / \mathrm{He}$-ICWC applied to erode carbon codeposits removed $6.6 \times 10^{21} \mathrm{C}$-atoms (39 pulses, $158 \mathrm{~s}$ cumulated discharge time). Large oxygen retention ( $71 \%$ of injected oxygen) prevented subsequent ohmic discharge initiation. Plasma operation was recovered by a $1 \mathrm{~h} 47 \mathrm{multi}-$ pulse $\mathrm{D}_{2}$-ICWC procedure including pumping time between pulses with duty cycle of $2 \mathrm{~s} / 20 \mathrm{~s}$, cleaning the vessel from oxygen impurities, followed by a 23 min He-ICWC procedure $(2 \mathrm{~s} / 20 \mathrm{~s})$, applied to desaturate the deuteriumloaded walls. A stable ohmic discharge was established on the first attempt right after the recovery procedure. The discharges showed improved density control and only slightly increased oxygen characteristic radiation levels (1-1.5 times). After the recovery procedure $36 \%$ of the injected O-atoms remained retained in the vessel, derived from mass spectrometry measurements. This amount is in the estimated range for storage in remote areas obtained from surface analysis of locally exposed samples. The removed amount of oxygen by $\mathrm{D}_{2}$ and He-ICWC obtained from mass spectrometry corresponds to the retention in plasma-wetted areas estimated by surface analysis. It is concluded that most of the removed oxygen stems from plasma-wetted areas while shadowed areas, e.g. behind poloidal limiters, may feature net retention of the discharge gas. On ITER, designed with a shaped first wall, the ICWC plasma-wetted area will approach the total surface area, reducing consequently the retention in remote areas. A tentative extrapolation of the carbon removal on TEXTOR to tritium removal from co-deposits on ITER in the $39 \times 4 \mathrm{~s} \mathrm{O}_{2} / \mathrm{He}-\mathrm{ICWC}$ discharges, including pumping time between the RF pulses, corresponds on ITER to a tritium removal in the order of the estimated retention per $400 \mathrm{~s}$ DT-burn (140-500 mgT (Shimada and Pitts $2011 \mathrm{~J}$. Nucl. Mater. 415 S1013-6)).
\end{abstract}

(Some figures may appear in colour only in the online journal)

\section{Introduction}

Discharge wall conditioning is an effective tool to improve plasma performance in tokamak and stellarator fusion research devices by (i) reducing the generation of plasma impurities liberated from the wall and (ii) controlling the recycling of hydrogenic fluxes. On ITER discharge wall conditioning will be employed as well for (iii) mitigating the tritium inventory build-up, for which one relies mostly on the removal of tritiumrich co-deposited layers. On carbon devices, it is known that the use of the reactive gas oxygen, either pure or oxygen/helium mixtures, is especially efficient for the removal of carbon 


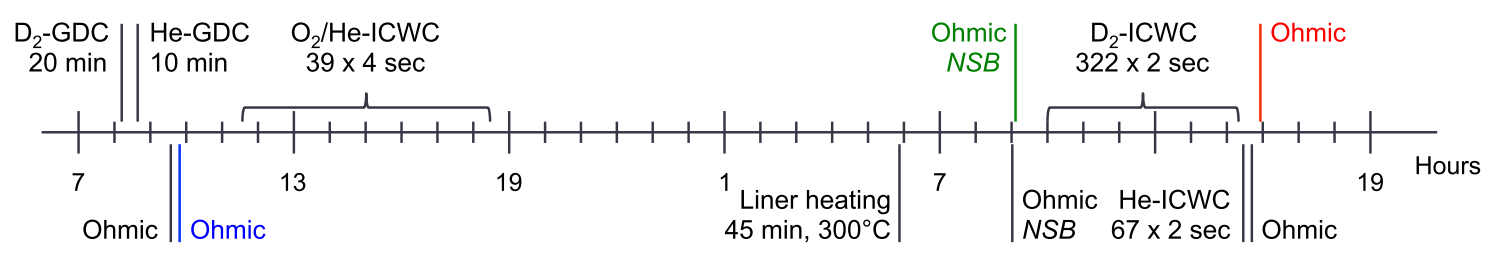

Figure 1. Chronology of the experiment. The density and gas consumption signals of the blue, green and red marked ohmic discharges are shown in figure 3.

deposits through the formation of $\mathrm{CO}$ and $\mathrm{CO}_{2}$ [1-3]. The concerned chemical reactions are

$$
\begin{gathered}
\mathrm{CH}_{n}+(1+n / 2) \mathrm{O} \rightarrow \mathrm{CO}+n / 2 \mathrm{H}_{2} \mathrm{O} \\
\mathrm{CH}_{n}+(2+n / 2) \mathrm{O} \rightarrow \mathrm{CO}_{2}+n / 2 \mathrm{H}_{2} \mathrm{O} .
\end{gathered}
$$

Although oxygen conditioning is very efficient for the removal of carbon deposits (e.g. $5.2 \mathrm{gC}$ in $4 \mathrm{~h} \mathrm{O}_{2}$-glow discharge conditioning (GDC) on TEXTOR [4]) and thus for tritium removal, large amounts of injected oxygen risk being retained on the wall surfaces, negatively affecting subsequent tokamak plasma performance or even prohibiting the start-up.

Ion cyclotron wall conditioning (ICWC) is a wellstudied discharge wall conditioning technique [5-7] having the advantage over GDC that it is applicable in the presence of magnetic fields. The ICWC mode of operation is included in the functional requirements of the ITER ion cyclotron resonance heating and current drive (ICRH\&CD) system [8], and will be employed on ITER during the operational cycles, i.e. when the toroidal magnetic field produced by superconducting magnetic coils is present.

This paper reports on a self-consistent application of $\mathrm{O}_{2} / \mathrm{He}-\mathrm{ICWC}$ for co-deposited layer removal followed by $\mathrm{D}_{2}$ and He-ICWC for recovering tokamak operation from the oxygen wall loading by $\mathrm{O}_{2} / \mathrm{He}-\mathrm{ICWC}$ on TEXTOR, and thereby treats all listed conditioning aims, respectively, aim (iii), (i) and (ii).

\section{Experimental setup}

TEXTOR with its circular plasma in limiter configuration is equipped with a toroidal graphite limiter (ALT-II), graphite poloidal limiters at the top and the bottom of the vessel, an inner graphite limiter (DED) and an inconel liner shell (held at $150^{\circ} \mathrm{C}$ ). Two limiter-lock ports mounted at different toroidal sections on the bottom and the top of the vessel allow easy positioning and exposure of material samples and diagnostic probes, facilitating the investigation of plasmasurface interactions (PSI) [9]. The fast reciprocating probe located in the outer midplane can also be used for surface sample exposure.

Among other heating systems TEXTOR is equipped with two double-loop ICRF (ion cyclotron range of frequencies) antennas, both able to provide $2 \mathrm{MW}$ of power at the generator. Antenna A1 has two poloidal straps, each consisting of three parallel tubes without a Faraday screen, and antenna A2 has two solid poloidal current straps with a Faraday screen. The
ICRH frequency range is $25-38 \mathrm{MHz}$. The straps of antennas $\mathrm{A} 1$ and $\mathrm{A} 2$ were phased, respectively, in dipole and monopole for this experiment. While the phasing is independent of the coupling for antenna A1, the phasing settled in vacuum for antenna A2 may shift depending on the coupling efficiency.

The toroidal magnetic field in TEXTOR is generated by water-cooled copper coils. To avoid overheating of these nonsuperconducting coils, operation is limited to pulsed mode at a nominal magnetic field $(\max 3 \mathrm{~T}$ with a duty cycle of approximately $10 \mathrm{~s}$ of operation and $5 \mathrm{~min}$ for cooling down). At low magnetic fields $(<0.4 \mathrm{~T})$ a steady-state toroidal magnetic field can be applied. The ability of maintaining such a steady-state magnetic field allows TEXTOR to perform long series of ICWC pulses, significantly increasing the achievable plasma exposure time per operational day.

The chronology of the presented experiment is summarized in figure 1 . The TEXTOR wall was prepared by 20 min of $\mathrm{D}_{2}-\mathrm{GDC}$ and $10 \mathrm{~min}$ of He-GDC prior to the ICWC experiment. Before the oxygen conditioning for co-deposited layer removal the initial state of the vessel was examined with two standard ohmic discharges $\left(I_{\mathrm{p}}=400 \mathrm{kA}, B_{\mathrm{T}}=1.9 \mathrm{~T}\right.$, $\left.n_{\mathrm{e}}=2 \times 10^{19} \mathrm{~m}^{-2}\right)$. During one operational day $39^{18} \mathrm{O}_{2} / \mathrm{He}-$ ICRF discharges were performed using a helium background pressure provided by constant gas feed ( $p_{\mathrm{He}}=10^{-4} \mathrm{mbar}$ ) while the oxygen injection was feedback controlled on the total pressure ( $p_{\text {tot }}=5 \times 10^{-4}$ mbar). It was chosen to use the oxygen-18 isotope to facilitate mass spectrometry and post-mortem surface analysis. The feedback control on the oxygen injection was set to maximize the discharge pressure, compensating for wall pumping. The helium base pressure improved the pressure control on discharge initiation and ensured safe operation of the antennae. Several discharge parameters were varied to investigate and optimize the ICWC plasma properties, aiming at maximized ion fluxes to the top and bottom limiter-locks. Surface samples were exposed in both limiter locks as well as in the midplane holder in the range $r=45-53 \mathrm{~cm}$ with the TEXTOR poloidal limiters being at $r=47.5 \mathrm{~cm}$. The total cumulated ICWC discharge time equalled $158 \mathrm{~s}$, at different ICRF powers of $P_{\mathrm{RF}}=$ [25 kW (1 discharge), $50 \mathrm{~kW}(27), 75 \mathrm{~kW}(1), 100 \mathrm{~kW}(10)]$, applied to antenna $\mathrm{A} 2$ at $29 \mathrm{MHz}$ with coupling efficiency ranging from $50 \%$ to $90 \%$, toroidal magnetic field values of $B_{\mathrm{T}}=$ [1.9 T (10 discharges), $-1.9 \mathrm{~T}(24), 0.23 \mathrm{~T}(3),-0.23 \mathrm{~T}(2)]$, and poloidal fields ranging from 0 to $2 \mathrm{mT}$.

On the next operational day two attempts for ohmic startup led to non-sustained breakdowns (NSBs) due to a high level of impurities in the vessel. For evidencing the wall conditioning effectiveness of ICWC, the recovery of TEXTOR 
Table 1. Oxygen balance: overview of the pumped gases measured by mass spectrometry during $\mathrm{O}_{2} / \mathrm{He}_{-} \mathrm{ICWC}$ and the recovery $\mathrm{D}_{2}$ and $\mathrm{He}-\mathrm{ICWC}$ procedure given in number of (\#) atoms or molecules, counting both ${ }^{16} \mathrm{O}$ and ${ }^{18} \mathrm{O}$ (chronology is given in figure 1 ). The negative values are calculated as removed minus injected oxygen.

\begin{tabular}{llllll}
\hline $\begin{array}{l}\text { Unit \# } \\
\text { at./mol. }\end{array}$ & $\begin{array}{l}\mathrm{O}_{2} / \mathrm{He}- \\
\text { ICWC }\end{array}$ & $\begin{array}{l}\text { Between } \\
\text { sessions }\end{array}$ & $\begin{array}{l}\mathrm{D}_{2-} \\
\text { ICWC }\end{array}$ & $\begin{array}{l}\mathrm{He}- \\
\text { ICWC }\end{array}$ & \multicolumn{1}{l}{$\begin{array}{l}\text { Total } \\
\text { balance }\end{array}$} \\
\hline O-atoms & $-2.6 \times 10^{22}$ & $9.3 \times 10^{21}$ & $3.9 \times 10^{21}$ & $1.6 \times 10^{20}$ & $-1.3 \times 10^{22}$ \\
$\mathrm{CO}$ & $5.8 \times 10^{21}$ & $1.4 \times 10^{21}$ & $1.2 \times 10^{21}$ & $3.1 \times 10^{19}$ & $8.4 \times 10^{21}$ \\
$\mathrm{CO}_{2}$ & $7.8 \times 10^{20}$ & $4.2 \times 10^{20}$ & $2.2 \times 10^{20}$ & $1.4 \times 10^{19}$ & $1.4 \times 10^{21}$ \\
Water & $8.4 \times 10^{20}$ & $7.0 \times 10^{21}$ & $2.3 \times 10^{21}$ & $1.2 \times 10^{20}$ & $1.0 \times 10^{22}$ \\
\hline
\end{tabular}

operation from this severely deteriorated wall purity state needs to be demonstrated. The ICWC procedure to achieve this consisted of $1 \mathrm{~h} 47$ of multi-pulse $\mathrm{D}_{2}$-ICWC and $23 \mathrm{~min}$ of multi-pulse He-ICWC. ICWC pulses of $2 \mathrm{~s}$ were repeated every $20 \mathrm{~s}$ maintaining constant discharge parameters. In total $322 \mathrm{D}_{2}$-ICWC pulses were performed at a steady-state low magnetic field $\left(B_{\mathrm{T}}=0.23 \mathrm{~T}\right)$, of which 210 were with feedback controlled $\mathrm{D}_{2}$ pressure $\left(p_{\mathrm{D}_{2}}=5 \times 10^{-4} \mathrm{mbar}\right)$, using both antennas at $f_{\mathrm{RF}}=29 \mathrm{MHz}$ and $P_{\mathrm{RF}, \mathrm{A} 1 \& \mathrm{~A} 2}=[2 \times$ $50 \mathrm{~kW}$ (260 pulses), $2 \times 100 \mathrm{~kW}$ (60 pulses)]. To desaturate the deuterium-loaded walls prior to the ohmic tokamak plasma operation, an additional $67 \mathrm{He}-\mathrm{ICWC}$ pulses were applied respecting the same RF duty cycle, magnetic field, antenna frequency, pressure and power $\left(P_{\mathrm{RF}, \mathrm{A} 1 \& \mathrm{~A} 2}=2 \times 50 \mathrm{~kW}\right)$. From the insignificant heating of the antenna structure, the absence of RF trips and metallic characteristic radiation, it was concluded that the RF systems worked safely and reliably throughout the whole conditioning procedure.

Two standard ohmic discharge attempts after the conditioning procedure were both successful, featuring good density control and proving the recovery of TEXTOR operation, as will be shown in section 4 .

\section{Oxygen balance}

\subsection{Mass spectrometry}

An estimate for the oxygen particle balance is obtained via mass spectrometry, and a summary is given in table 1 . From the carbon removal during $\mathrm{O}_{2}$-ICWC a figure of merit is derived for the achievable T-removal on ITER in the next section. Working with oxygen-18 as the discharge gas enabled the use of the low background mass spectrometry signals for $\mathrm{C}^{18} \mathrm{O}$ (mass 30) and $\mathrm{C}^{18} \mathrm{O}_{2}$ (mass 48) and presented an unambiguous marker for surface analysis. Nevertheless, for the oxygen balance, the injected amount of oxygen needs to be compared with the total removed amount of oxygen isotopes. As such the ${ }^{18} \mathrm{O}_{2}$ discharges can be considered to effectuate oxygen isotopic exchange on the TEXTOR wall, which is relatively abundantly loaded with ${ }^{16} \mathrm{O}$. The latter abundance is illustrated by the stable isotopic ratios throughout the experiment, estimated from the high mass spectrometry signals for $\mathrm{C}^{16} \mathrm{O}$ and $\mathrm{C}^{18} \mathrm{O}$, as well as for the weaker $\mathrm{C}^{16} \mathrm{O}_{2}$ and $\mathrm{C}^{18} \mathrm{O}_{2}$ signals (masses 28 , 30,44 and 48, respectively) taken in the outgassing peak after the ICWC discharge termination, shown in figure $2(b)$.

The oxygen-18 consumption in the $39 \mathrm{O}_{2} / \mathrm{He}-\mathrm{ICWC}$ discharges amounted to $3.6 \times 10^{22} \mathrm{O}$-atoms, decaying over 15 discharges from about $2.3 \times 10^{21}$ atoms/discharge in the first 3 discharges to $7.7 \times 10^{20}$ atoms/discharge in the last 20 discharges (shown in figure $2(a)$ ). This typical initial

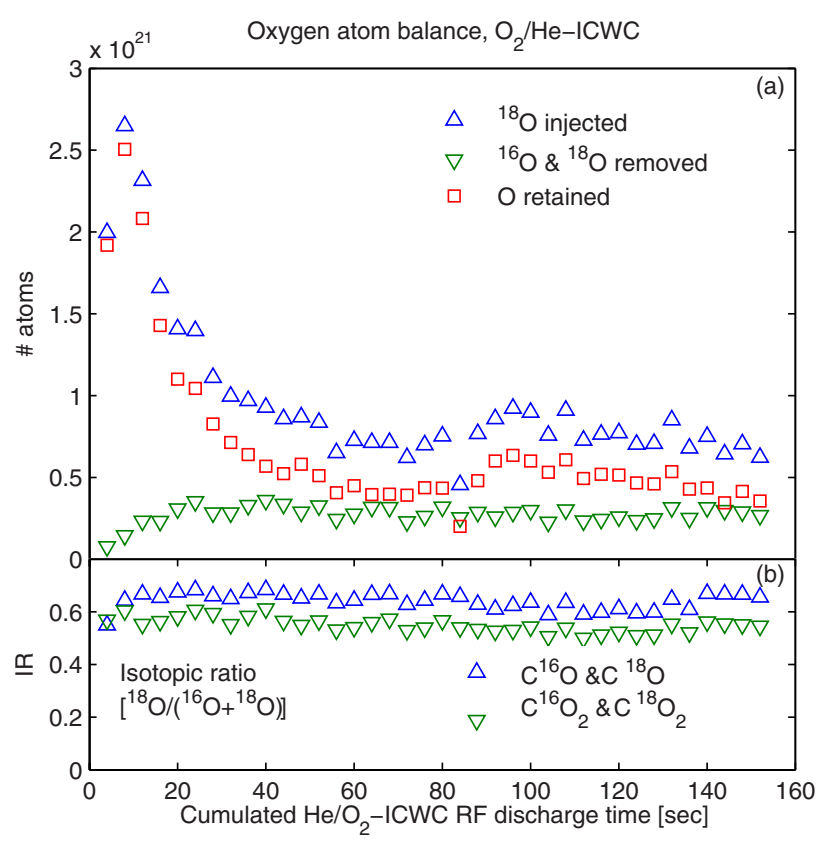

Figure 2. (a) Oxygen balance of the $\mathrm{O}_{2} / \mathrm{He}-\mathrm{ICWC}$ discharges for co-deposited layer removal. The oxygen retention in TEXTOR saturates after $60 \mathrm{~s}$ of plasma, reaching an equilibrium between retention and recovery. (b) The oxygen isotopic ratio of the wall-desorbed gas after ICWC discharge termination remains stable around $60 \%$ indicating the abundant presence of ${ }^{16} \mathrm{O}$ in TEXTOR.

wall saturation effect has been observed as well in $\mathrm{H}_{2}$-ICWC discharges in TEXTOR [5, 7]. Where the oxygen consumption remained stable only about $30 \%$ of the injected oxygen could be recovered, mostly as $\mathrm{CO}$ and $\mathrm{CO}_{2}$. In total, $7.3 \pm 1.8 \times 10^{21}$ oxygen atoms were pumped as $\mathrm{CO}$ or $\mathrm{CO}_{2}$ (both ${ }^{16} \mathrm{O}$ and ${ }^{18} \mathrm{O}$ ) while $2.2 \times 10^{21} \mathrm{O}$-atoms were removed as $\mathrm{O}_{2}$, and only $8.4 \times 10^{20} \mathrm{O}$-atoms as water (including isotopes $\mathrm{H}, \mathrm{D},{ }^{16} \mathrm{O}$ and ${ }^{18} \mathrm{O}$ ), as derived from mass spectrometry measurements. This high removal of $\mathrm{O}$ as $\mathrm{CO}$ and $\mathrm{CO}_{2}(70 \%)$ is in agreement with previous reports on TEXTOR $\mathrm{O}_{2}$-ICWC discharges [3]. The errors of the mass spectrometry analysis are considerable, estimated to up to $25 \%$ for $\mathrm{CO}$ and $\mathrm{CO}_{2}$ and possibly higher for $\mathrm{H}_{2} \mathrm{O}$ solely due to incomplete calibration data. The calculated partial pressures are consistent with the total pressures.

After the $\mathrm{O}_{2} / \mathrm{He}-\mathrm{ICWC}$ operation $71 \%$ of the injected O-atoms remained retained in the wall $\left(2.6 \times 10^{22}\right)$. Between the two experimental days the partial pressures were continuously monitored. The partial pressures in this period corresponded to a removal of $2.2 \times 10^{21} \mathrm{O}$-atoms as $\mathrm{CO}$ and $\mathrm{CO}_{2}$, and a significant amount of $7.0 \times 10^{21} \mathrm{O}$-atoms in the form of water. About $50 \%$ of these molecules were retrieved during 
the standard nightly heating of the liner $\left(45 \mathrm{~min}\right.$ at $\left.300^{\circ} \mathrm{C}\right)$. The remaining retained oxygen at the start of the $\mathrm{D}_{2}$ and $\mathrm{He}-\mathrm{ICWC}$ recovery procedure equalled $1.7 \times 10^{22} \mathrm{O}$-atoms, or $47 \%$ of the injected amount. The non-sustained ohmic breakdowns preceding the recovery ICWC discharges indicate that this amount is too much to allow the ohmic start-up. The discharge attempts themselves removed a negligible amount of oxygen: $0.1 \times 10^{18} \mathrm{O}$-atoms as $\mathrm{CO}$ and $\mathrm{CO}_{2}, 1.7 \times 10^{19} \mathrm{O}$-atoms as water.

The majority of the retrieved oxygen in the recovery wall conditioning procedure was pumped during the $1 \mathrm{~h} 47$ multipulse $\mathrm{D}_{2}$-ICWC procedure: in total, $2.3 \times 10^{21}$ water molecules and an expected lower amount of $1.6 \times 10^{21} \mathrm{O}$-atoms as $\mathrm{CO}$ and $\mathrm{CO}_{2}$. The 23 min multi-pulse He-ICWC procedure, aimed at desaturating the walls of hydrogen isotopes to ensure successful ohmic start-up and good density control, removed $1.6 \times 10^{20} \mathrm{O}$-atoms.

At the end of the recovery procedure still $1.3 \times 10^{22}$ $\mathrm{O}$-atoms remained retained in the wall. This corresponds to $36 \%$ of the injected amount, or $49 \%$ of the initially retained O-atoms.

\subsection{Surface analysis}

Radial profiles of ${ }^{18} \mathrm{O}$ deposition were taken from exposed cut-outs from TEXTOR DED tiles (carbon) on the midplane holder and several aluminum- and carbon-coated silicon samples on the limiter-locks using the ${ }^{18} \mathrm{O}(\mathrm{p}, \alpha){ }^{15} \mathrm{~N}$ nuclear reaction at $2 \mathrm{MeV}$. The samples were exposed in the range $r=45-53 \mathrm{~cm}$ with the TEXTOR poloidal limiters being at $r=47.5 \mathrm{~cm}$. Around this radius $(r=47-48 \mathrm{~cm})$ an average of $(11.7 \pm 5.7) \times 10^{15}{ }^{18} \mathrm{O} \mathrm{cm}^{-2}$ was found on a DED sample parallel to $B_{\mathrm{T}}$, while on shadowed areas $(r=50-$ $53 \mathrm{~cm})$ deposition concentrations ranging from $5.6 \times 10^{15}$ to $29 \times 10^{1518} \mathrm{O} \mathrm{cm}^{-2}$ were found. On an aluminum-coated sample from the top limiter-lock a lower deposition of $2.8 \pm$ $0.5 \times 10^{1518} \mathrm{O} \mathrm{cm}^{-2}$ at $r=47 \mathrm{~cm}^{2}$ was found. These local deposition concentrations can be tentatively extrapolated to the whole TEXTOR first wall. Using the surface area of the ALT-II and the inner DED limiter (area of $3.4+11 \mathrm{~m}^{2}$ ) this results in a total inventory of $1.7 \pm 0.5 \times 10^{2118} \mathrm{O}$-atoms stored in plasmawetted surfaces. For storage in remote areas, by taking the obtained areal ${ }^{18} \mathrm{O}$ densities on the metal $(\mathrm{Al})$ surface as the lower and the retention in the shadowed carbon samples as the upper limit, a broad inventory range between $6.7 \times 10^{20}$ and $1.1 \times 10^{22}{ }^{18} \mathrm{O}$-atoms is estimated. It is noted that this estimation suffers from poor knowledge of the effective remote area (open liner area: $24-38 \mathrm{~m}^{2}$ ), its surface composition and the plasma wall flux homogeneity. All values in the above surface analysis were corrected for the natural ${ }^{18} \mathrm{O}$ isotopic content. Changes in ${ }^{16} \mathrm{O}$ content were not detectable due to high background values in the exposed samples. With the measured neutral gas oxygen isotope ratio of $60 \%{ }^{18} \mathrm{O}$ (figure $2(b)$ ) a total amount of $2.8 \pm 1.3 \times 10^{21} \mathrm{O}$-atoms is estimated to be stored in the main PFCs and $1.1 \times 10^{21}$ $1.8 \times 10^{22} \mathrm{O}$-atoms in remote areas.

The surface analysis estimation for the amount of oxygen to be found on the plasma-wetted surfaces shows agreement with the amount of oxygen recovered by $\mathrm{D}_{2}$-ICWC obtained from mass spectrometry. The remaining oxygen retention as

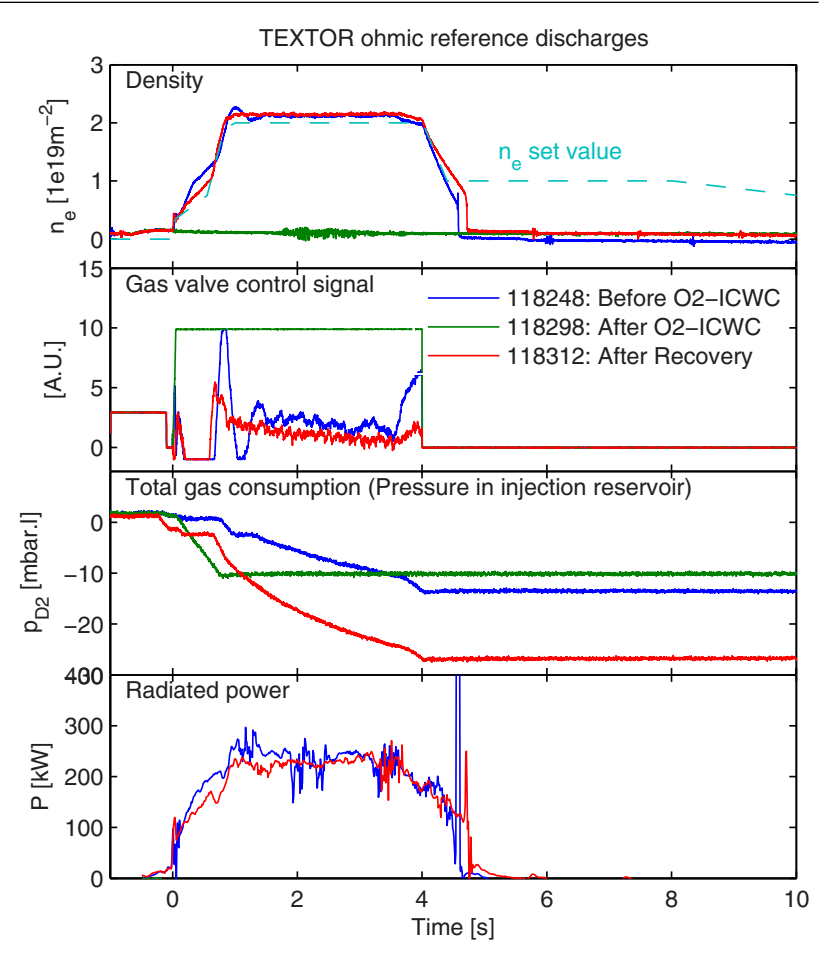

Figure 3. Recovery of TEXTOR operation after $\mathrm{O}_{2}$-conditioning using multi-pulse $\mathrm{D}_{2}$-ICWC and He-ICWC. Top to bottom: density, density control signal, total gas consumption and radiated power of ohmic discharges before $\mathrm{O}_{2} / \mathrm{He}-\mathrm{ICWC}$ (blue), and before (green, NSB) and after the recovery conditioning procedure consisting of 1 h47 of $\mathrm{D}_{2}$-ICWC and 23 min of He-ICWC (red). The chronology of the experiment is shown in figure 1 .

determined from mass spectrometry is in the obtained range for storage in remote areas estimated by surface analysis. Both these findings support the assumption of predominant oxygen recovery from surfaces with plasma contact. The estimated range by surface analysis for the total oxygen retention after $\mathrm{O}_{2} / \mathrm{He}-\mathrm{ICWC}$ operation has large uncertainties due to scatter in the measured areal oxygen densities, but covers the value obtained by mass spectrometry: $3.9 \times 10^{21}$ $2.1 \times 10^{22}$ versus $(1.7 \pm 0.5) \times 10^{22}$. Further detailed surface analysis is presented in [14]. Co-deposit removal from castellation gaps could not be assessed in this experiment. First results from TOMAS and KSTAR are however presented, respectively, in $[15,16]$.

\section{Plasma restart after oxygen removal by ICWC}

Figure 3 shows the density and gas consumption of the ohmic discharge $\left(I_{\mathrm{p}}=400 \mathrm{kA}, n_{\mathrm{e}}=2 \times 10^{19} \mathrm{~m}^{-2}, B_{\mathrm{T}}=1.9 \mathrm{~T}\right)$ right before $\mathrm{O}_{2} / \mathrm{He}-\mathrm{ICWC}$ (blue), and those ran before (green) and after the recovery by $\mathrm{D}_{2}$ and $\mathrm{He}-\mathrm{ICWC}$ (red). The NSBs after $\mathrm{O}_{2} / \mathrm{He}$-ICWC were due to high electron cooling by $\mathrm{O}$-impurities. The particle balance presented in the previous section concluded that after the recovery wall conditioning procedure still a significant amount of oxygen was stored in the vessel walls (540 mbar 1). Nevertheless, a stable ohmic discharge has been established in the first attempt. As figure 3 illustrates, the density control via gas injection was very good during this ohmic discharge: the density followed the set value very well, the valve control signal had little oscillation 


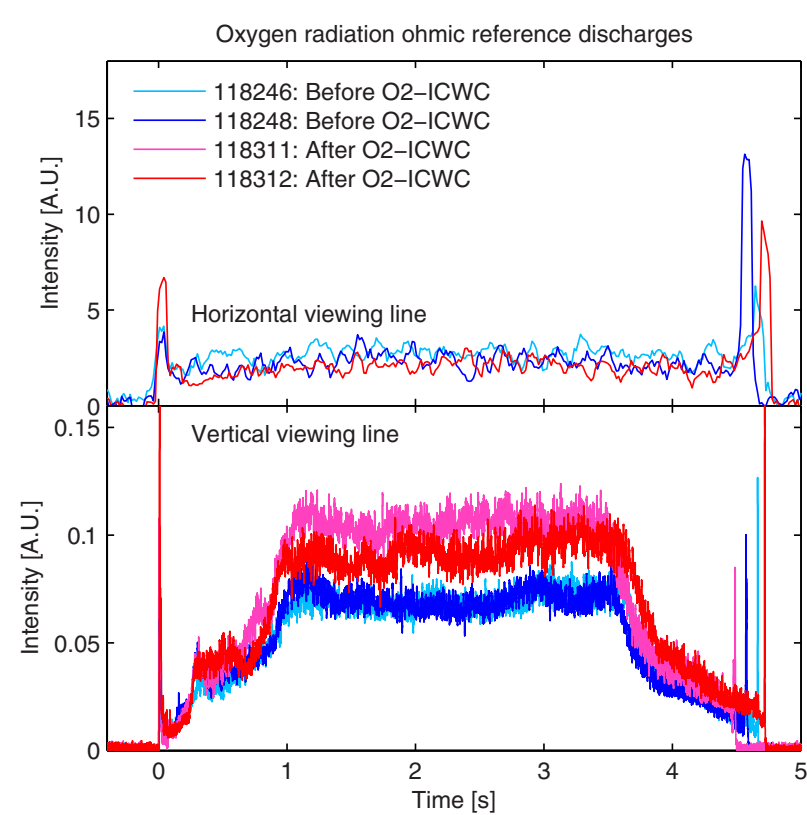

Figure 4. Characteristic oxygen radiation time traces of ohmic discharges before $\mathrm{O}_{2}$-conditioning and after the recovery procedure by ICWC. A small but systematic increase in the oxygen radiation level can be seen. Top: horizontal viewing line looking at the ICRH antenna A2 (O II at $442 \mathrm{~nm}$ ), bottom: vertical viewing line looking at the ALT-II limiter (O I at $777.5 \mathrm{~nm})$.

and the high gas consumption evidenced low recycling fluxes from the wall. For a similar ohmic power level, the radiated power fraction was even slightly lower after recovery (figure 3, bottom).

Characteristic oxygen radiation time traces measured along two viewing lines are plotted in figure 4 . The horizontal chord (top figure) looking at the ICRH antenna A2 showed no increased oxygen radiation during the discharge. The ICRF antennas were not operated during the ohmic discharges and the detected radiation values were close to the noise level. At the end of the controlled current ramp-down however the plasma visibly (CCD camera images) interacted with the antenna structure resulting in the measured oxygen radiation peak. The peak was twice as high for the first discharge after the recovery (\#118311) compared with the ohmic discharge right before the $\mathrm{O}_{2} / \mathrm{He}-\mathrm{ICWC}$ experiment (\#118748). Even though the height of such peaks is sensitive to the specific discharge termination, this difference is most likely related to the remaining oxygen in the vessel. The difference was clearer for the characteristic oxygen line recorded by a vertical chord (bottom figure) looking at the toroidal belt limiter (ALT-II). The integral of the signal over the current flat top phase gives an overall oxygen radiation increase by a limited factor of 1.5 in the first recovered discharge (\#118311), decreasing to 1.3 in the second (\#118312), giving further evidence for oxygen storage in remote areas.

\section{Discussion and implications for ITER}

The remaining oxygen retention after the recovery conditioning procedure did not prevent ohmic breakdown. This suggests that ICWC has sufficiently conditioned the wall surfaces that are in close contact with the ohmic plasma in the different phases of the discharge, while the remaining oxygen is stored in more remote areas. The surfaces in contact with the plasma are the poloidal limiters, the toroidal ALT-II limiter and the inner DED target limiter. It is known that the plasma density in ICWC plasmas decreases exponentially close to the vessel walls where the magnetic field lines are limited by wall structures [10]. Consequent to the existence of this edge plasma, the ion wall flux will be largest on the first limiting surfaces, being the same surfaces in contact with the plasma during tokamak discharges on TEXTOR. While the areas receiving the conditioning flux are cleaned efficiently, the shadowed areas likely feature net retention of discharge gas during the conditioning procedure. In such a case the RF duty cycle may be adapted so that little wall-desorbed particles are re-deposited [11]. Unlike on present devices, on ITER the ion wall flux is expected to be more homogeneous since no dedicated poloidal limiting structures other than the shaped first wall itself will be present in the vessel [12]. Consequently, the ICWC plasma edge, as it exists on present devices, will not exist on ITER making the storage in remote areas less important.

The feasibility of wall conditioning with oxygen for tritium removal hinges upon the amount of tritiated products (e.g. water) produced in the process. Assuming a typical hydrogen isotope concentration of $0.4 \mathrm{H}$-isotopes/C-atom in tokamak carbon co-deposits [13] and a fusion fuel isotopic ratio of $50 \%(\mathrm{~T} /(\mathrm{D}+\mathrm{T}))$ the estimated $6.6 \times 10^{21}$ carbon atoms removed as $\mathrm{CO}$ or $\mathrm{CO}_{2}$ during $\mathrm{O}_{2} / \mathrm{He}-\mathrm{ICWC}$ (table 1) translate into a potential tritium removal from co-deposits of $1.3 \times 10^{21}$ atoms or $6.6 \mathrm{mgT}$ in the $39 \times 4 \mathrm{~s}$ discharges. The actually pumped amount of $\mathrm{H}$-isotopes as water $(1.7 \times$ $10^{21}$ atoms, table 1$)$ and molecular hydrogen $\left(4.2 \times 10^{21}\right.$ atoms), $5.4 \times 10^{21}$ atoms in total, exceeds and may thus include the two times $1.3 \times 10^{21} \mathrm{D}$ and $\mathrm{T}$ isotopes stemming from co-deposits. The direct comparison between these two quantities is however more complicated as characteristic times for e.g. desorption, ionization, dissociation and pumping are different for the considered molecules. Pumping of methane or heavier hydrocarbon molecules is not included in this analysis as it is considered only small in these O-abundant plasmas. The carbon and simulated tritium removal rate on TEXTOR is evaluated accounting for sufficient time between pulses to pump the relevant wall-desorbed molecules, approximately three characteristic pumping times. With an optimal RF duty cycle of $4 \mathrm{~s} / 60 \mathrm{~s}$ for $\mathrm{CO}, \mathrm{CO}_{2}$ and water removal, this results in $0.2 \mathrm{gC} \mathrm{h}^{-1}$ and $10 \mathrm{mgT} \mathrm{h}^{-1}$ on TEXTOR. A tentative extrapolation for the achievable T-removal from co-deposits in $39 \times 4 \mathrm{~s}$ pulses on ITER, taking into account the TEXTOR (C: $3.4+11 \mathrm{~m}^{2}$, liner: $\left.\max .38 \mathrm{~m}^{2}\right)$ and ITER (Be: $700 \mathrm{~m}^{2}$, W: $100 \mathrm{~m}^{2}$ [13]) wall surface areas, delivers promising results although at this point the dependence on the surface material is neglected. An extrapolation from TEXTOR C-area to ITER $\mathrm{W}$-area supposes that the gross of the deposits are located in the divertor area, resulting in a removal of $46 \mathrm{mgT}$, which can be considered as a lower estimate. Extrapolating from total TEXTOR C + liner-area to total ITER $\mathrm{W}+\mathrm{Be}-$ area gives $100 \mathrm{mgT}$. This value corresponds to a removal rate of $0.16 \mathrm{gTh}^{-1}$. An upper value, extrapolating from TEXTOR C-area to ITER W + Be-area, assumes additional tritium storage on the ITER beryllium first wall. This shaped surface, belonging to the ICWC plasma-wetted area, ensures 
access to the storage areas resulting in a possible removal of up to $370 \mathrm{mgT}$. All three estimates are close to or in the range of the estimated retention per $400 \mathrm{~s}$ DT-burn (140-500 mgT [1]).

The prospect of using oxygen discharge conditioning is not certain for the nuclear phase of ITER. The oxygen discharges imply production of large quantities of tritiated water (DTO), which may feature enhanced production of extremely corrosive peroxides and is possibly beyond what the ITER Tokamak Exhaust Processing plant can handle. Moreover, the use of large quantities of oxygen in the exhaust gas is excluded for safety reasons [1].

Regardless of the applicability of $\mathrm{O}_{2}$-ICWC on ITER, the value of the presented experiment lies largely in the successful tokamak operation recovery by $\mathrm{D}_{2}$ and He-ICWC. The ITER vacuum vessel can be (oxygen, etc) contaminated from uncontrolled sources (e.g. leaks, replacement materials, accidental events, etc). ICWC may be envisaged for recovering machine operation after such events. Demonstrating the operational effectiveness of ICWC is naturally required for consolidating the technique prior to its application on ITER. Earlier successful demonstrations are the recovery by $\mathrm{He}-$ ICWC after disruptions on Tore Supra [17] and the promising inter-pulse conditioning results on KSTAR [18], where HeICWC was used in order to keep the vessel $\mathrm{H}_{2} \mathrm{O}$ pressure below the operational limit.

\section{Conclusion}

ICWC will be used on ITER during operational phases, i.e. in the presence of the toroidal magnetic field, for reducing the generation of plasma impurities, controlling the recycling of hydrogenic fluxes and for mitigating the tritium inventory build-up by removing tritium-rich co-deposited layers. The presented TEXTOR experiment is considered a self-consistent demonstration covering all of the above wall conditioning aims. $\mathrm{O}_{2} / \mathrm{He}-\mathrm{ICWC}$ was applied to erode carbon co-deposits, removing $6.6 \times 10^{21} \mathrm{C}$-atoms (39 pulses, $158 \mathrm{~s}$ cumulated discharge time). The large oxygen retention however, namely $71 \%$ of the injected oxygen, prevented subsequent ohmic discharge initiation. A $1 \mathrm{~h} 47$ multi-pulse $\mathrm{D}_{2}$-ICWC procedure effectively cleaned the main plasma-facing components from oxygen impurities whereafter $23 \mathrm{~min}$ of multi-pulse He-ICWC was applied to desaturate the deuterium-loaded walls. The successful tokamak operation recovery could be demonstrated by establishing stable ohmic discharges on the first attempt right after the recovery procedure. The discharges showed improved density control compared with the reference discharges. The oxygen characteristic radiation had only slightly increased (1-1.5 times) with respect to the discharges before $\mathrm{O}_{2} / \mathrm{He}-\mathrm{ICWC}$ even though the oxygen balance by mass spectrometry suggested that after the recovery still $36 \%$ of injected O-atoms were retained in the vessel. This amount is in the estimated range for storage in remote areas obtained from surface analysis of locally exposed samples. The removed amount of oxygen by $\mathrm{D}_{2}$ and $\mathrm{He}$-ICWC corresponds to the retention in plasmawetted areas estimated by surface analysis. Based on these results it is concluded that due to ion transport along toroidal magnetic field lines, the first field line intersecting components receive the highest conditioning flux and are cleaned efficiently. Shadowed areas, e.g. behind poloidal limiters, may feature net retention of the discharge gas. On ITER, designed with a shaped first wall, the ICWC plasma-wetted area will approach the total surface area, reducing consequently the total retention in remote areas. A tentative extrapolation of the carbon removal on TEXTOR to tritium removal from co-deposits on ITER in the $39 \times 4 \mathrm{~s} \mathrm{O}_{2} / \mathrm{He}$-ICWC discharges, including pumping time between the RF pulses to remove walldesorbed gases, corresponds on ITER to a tritium removal in the order of the estimated retention per $400 \mathrm{~s}$ DT-burn (140-500 mgT).

\section{Acknowledgments}

This work was supported by EURATOM and carried out within the framework of the European Fusion Development Agreement. The views and opinions expressed herein do not necessarily reflect those of the European Commission.

\section{References}

[1] Shimada M. and Pitts R.A. 2011 J. Nucl. Mater. 415 S1013-16

[2] Dylla H.F. 1988 J. Vac. Sci. Technol. A 6 1276-87

[3] Sergienko G. 2009 J. Nucl. Mater. 390-391 979-82

[4] Philipps V. 2007 J. Nucl. Mater. 363-365 929-32

[5] Wauters T. 2011 Study and optimization of magnetized ICRF discharges for tokamak wall conditioning and assessment of the applicability to ITER PhD Thesis Ghent University, https://biblio.ugent.be/publication/1978443

[6] Lyssoivan A. 2012 Plasma Phys. Control. Fusion 54074014

[7] Douai D. et al 2012 Proc. 24th Int. Conf. on Fusion Energy 2012 (San Diego, CA, 2012) EX/P5-09 and www-naweb. iaea.org/napc/physics/FEC/FEC2012/index.htm

[8] Beaumont B. 2009 ITER ICRF system: R\&D progress and technical choices Proc. 23rd IEEE/NPSS Symp. on Fusion Engineering SOFE 2009 (San Diego, CA, 2009) (doi:10.1109/FUSION.2009.5226425)

[9] Schweer B. 2005 Fusion Sci. Technol. 47 138-45 www.ans.org/pubs/journals/fst/a_695

[10] Wauters T. 2011 Plasma Phys. Control. Fusion 53125003

[11] Wauters T. 2011 J. Nucl. Mater. 415 S1033-6

[12] Mitteau R. 2011 J. Nucl. Mater. 415 S969-72

[13] Roth J. 2008 Plasma Phys. Control. Fusion 50103001

[14] Carrasco A.G. 2013 Impact of ion cyclotron wall conditioning on fuel removal from plasma-facing components at TEXTOR Proc. PMFC-14 (Jülich, Germany, 13-17 May 2013) Phys. Scr. submitted www.fz-juelich.de/PFMC-14

[15] Schulz C. 2011 J. Nucl. Mater. 415 S781-4

[16] Douai D. 2013 Ion cyclotron wall conditioning in KSTAR and ASDEX-Upgrade Proc. 39th EPS Conf. on Plasma Physics (Helsinki, Finland, 2013) vol 40 (ECA) http://ocs.ciemat.es/EPS2013ABS/pdf/P2.120.pdf

[17] Douai D. 2011 J. Nucl. Mater. 415 S1021-8

[18] Sungwoo K. 2011 Fusion Sci. Technol. 60 98-101 www.ans.org/pubs/journals/fst/a_12413 